\title{
cAMP Levels Increased by Activation of Metabotropic Glutamate Receptors Correlate with Visual Plasticity
}

\author{
Silvia N. M. Reid, Nigel W. Daw, Douglas S. Gregory, and Helen Flavin \\ Department of Ophthalmology and Visual Science, Yale University School of Medicine, New Haven, \\ Connecticut 06520-8061
}

\begin{abstract}
We have investigated the cAMP level increased by stimulation of metabotropic glutamate receptors (mGluRs) in cat visual cortex during development. The cAMP level increases activated by the general mGluR agonist (1S,3R)-1-amino-1,3cyclopentane-dicarboxylic acid (ACPD) were closely correlated with the critical period for ocular dominance plasticity in both light- and dark-reared animals. Activation of either group I or group II mGluRs increased the cAMP level. Group II mGluR activation also reduced the forskolin-stimulated cAMP increase. The correlation was emulated by a mixture of groups I, II, and III mGluR agonists but not by agonists applied singly; therefore, the correlation is attributable to activation of multiple groups of mGluRs. The cAMP level increased by the mixture was greater than the sum of the increases produced by the
\end{abstract}

Deprivation of visual input from one eye can result in elaboration of connections from the open eye and withdrawal of connections from the deprived eye in the visual cortex (Wiesel and Hubel, 1963; Hubel et al., 1977). This ocular dominance plasticity is an example of the activity-dependent modification of synaptic connections. Both the afferents that carry visual inputs into the cortex and the dendritic structure of cortical neurons participate in this reorganization of the connections (Valverde, 1968; Shatz and Stryker, 1978; Antonini and Stryker, 1993). The information that leads to the change in the connections is carried into the visual cortex by action potentials (Stryker and Harris, 1986). To convert the information in action potentials into growth of dendrites requires intracellular messengers, and to convey the signal to geniculocortical afferents requires a feedback factor, which is probably also activated by second messengers.

Evidence suggests that the cAMP pathway mediates plasticity in various systems in a variety of animals (Schacher et al., 1988; Frey et al., 1993; Frank and Greenberg, 1994; Stevens, 1994). This signal transduction pathway is crucial in the late phase and in the maintenance phase of long-term potentiation (Frey et al., 1993; Matthies and Reymann, 1993) and is involved in long-term facilitation of connections between neurons in Aplysia where protein synthesis is required (Schacher et al., 1988). Therefore, this path-

\footnotetext{
Received May 15, 1996; revised Sept. 5, 1996; accepted Sept. 18, 1996.

This work was supported by U.S. Public Health Service Grant RO1 EY 00053 and a Human Frontier Science Program grant. We thank Dr. P. Jeff Conn for his generous gift of DCG-IV and discussion, Drs. Colin Barnstable and Peter Kind for their comments on this manuscript, and Dr. Ethan Cohen for his helpful suggestions.

Correspondence should be addressed to Nigel W. Daw, Department of Ophthalmology and Visual Science, Yale University School of Medicine, P.O. Box 208061, 330 Cedar Street, New Haven, CT 06520-8061.

Copyright (C) 1996 Society for Neuroscience $0270-6474 / 96 / 167619-08 \$ 05.00 / 0$
}

agonists applied singly (super-additive effect), suggesting an interaction between the G-proteins and/or second messengers controlled by these mGluRs. The basal cAMP level also correlated closely with the critical period until shortly after the peak of the critical period. Therefore, the major factor that contributes to the correlation between the ACPD-stimulated CAMP increase and the peak of the critical period is the basal level of CAMP: the activation of multiple mGluRs amplifies the basal CAMP. We suggest that both basal activity of cAMP production and activation of mGluRs may be important in plasticity in the visual cortex.

Key words: ocular dominance; signal transduction; area 17; critical period; secondary messenger; visual cortex

way may also participate in the remodeling of eye-specific connections.

Involvement of metabotropic glutamate receptors (mGluRs) in the activity-dependent modification of synaptic transmission has been implicated in the hippocampus (McGuinness et al., 1991; Otani and Ben-Ari, 1991; Bashir et al., 1993; Behnisch and Reymann, 1993; Musgrave et al., 1993), cerebellum (Hartell, 1994), and visual cortex (Kato, 1993; Haruta et al., 1994). mGluRs are categorized into three groups (I, II, and III) according to their agonist preference and their effects on second-messenger systems (Nakanishi, 1992; Schoepp and Conn, 1993; Joly et al., 1995). Activation of group I mGluRs, which prefer quisqualate over trans-1-aminocyclopentane-1,3-dicarboxylate, leads to hydrolysis of phosphoinositide (PI) and increased cAMP level. Activation of either trans-1-aminocyclopentane-1,3-dicarboxylatepreferring group II mGluRs or L-AP4-preferring group III mGluRs leads to suppression of forskolin-stimulated cAMP elevation. Regardless of group, every known mGluR can regulate cAMP levels. This leads to the speculation that mGluRs could act through cAMP to modulate plasticity.

Ocular dominance plasticity occurs during a critical period, starting around the third postnatal week, peaking between the fourth and the sixth postnatal week, dropping to a plateau around the 15th postnatal week, and ending around 1 year of age in cats (Olson and Freeman, 1980; Daw et al., 1992). Rearing animals in total darkness postpones this critical period (Cynader and Mitchell, 1980; Mower, 1991) so that the visual cortex of a dark-reared animal is less plastic than normal at 5 postnatal weeks, equally plastic around 8 postnatal weeks, and more plastic after 12 postnatal weeks of age (Mower, 1991). Thus, a factor that is involved in ocular dominance plasticity should have different effects at different ages in light- and dark-reared animals. 
In this study, we apply the above criterion to test whether the mGluR-regulated cAMP level may be related to ocular dominance plasticity. We find that mGluR activation by a general mGluR agonist leads to an increase of cAMP level with a time course that fits the critical period well in both light- and darkreared animals. Interestingly, the basal level of cAMP, defined as the level of cAMP in the absence of any stimulation by agonists or inhibition by antagonists, also correlated with the critical period quite well.

\section{MATERIALS AND METHODS}

Eighteen cats at various ages were used in this study. One normal cat per ages of $13,14,35,36,59,60,107,109,276$, and $294 \mathrm{~d}$ as well as two adult cats $(>3$ years of age) were used. Six other cats were dark-reared with their mother in light-tight cages in a darkened room. They were placed in darkness starting at 3-11 d of age, before their eyes opened, until they were $35,36,60,61,108$, or $109 \mathrm{~d}$ of age. It was clear from daily monitoring and from the condition of the animals when they were brought into the light that they maintained excellent health in the dark.

After deep anesthetization with ketamine and barbiturate, each animal was perfused with ice-cold, oxygenated artificial CSF (ACSF; NaCl, 128 $\mathrm{mM} ; \mathrm{KCl}, 2.5 \mathrm{~mm} ; \mathrm{MgSO}_{4}, 2 \mathrm{~mm} ; \mathrm{NaH}_{2} \mathrm{PO}_{4}, 1.25 \mathrm{~mm}$; glucose, $10 \mathrm{~mm}$; $\mathrm{NaHCO}_{3}, 26 \mathrm{~mm} ; \mathrm{CaCl}_{2}, 2 \mathrm{~mm}, \mathrm{pH}$ 7.3). The visual cortices were removed and sectioned on a vibratome at $400 \mu \mathrm{m}$. After recovering in ACSF in an oxygenated interface chamber ( $\sim 2 \mathrm{hr}$, at room temperature), each slice of the lateral gyrus was transferred into an individual incubation chamber containing $500 \mu \mathrm{l}$ of ACSF, and then drugs were added to achieve specific concentrations.

To activate group I mGluRs, quisqualate, (RS)-3,5-dihydroxyphenylglycine (DHPG), and the combination of (S)-4-carboxy-3-hydroxyphenylglycine (4C3HPG) and (RS)- $\alpha$-methyl-4-carboxyphenylglycine (MCPG) were used in this study. Two drugs, (2S,1'S,2'S)-2(carboxycyclopropyl) glycine (L-CCG-I) and $\left(2 \mathrm{~S}, 1^{\prime} \mathrm{R}, 2^{\prime} \mathrm{R}, 3^{\prime} \mathrm{R}\right)-2-(2,3-$ dicarboxycyclopropyl)glycine (DCG-IV), were used to activate group II mGluRs. L(+)-2-amino-4-phosphonobutyric acid (L-AP4) was used to activate group III mGluRs. A general mGluR agonist, (1S,3R)-1-amino1,3-cyclopentane-dicarboxylic acid (ACPD), was used at $0.5 \mathrm{~mm}$ to activate all three groups of mGluRs (Schoepp and Conn, 1993). A combination of quisqualate, L-CCG-I, and L-AP4 was also used to activate all three groups of mGluRs.

In an earlier study with rat visual cortex, we found that quisqualate at 0.1-0.5 mM was effective in elevating cAMP level (Flavin et al., 1996). When quisqualate $(0.25 \mathrm{~mm})$ was used in this study, 6-nitro-7sulfamoylbenzo[f]quinoxaline-2,3-dione (NBQX) and D(-)-2-amino-5phosphonopentanoic acid (APV) were also used to counteract the effect of quisqualate on AMPA/kainate and NMDA receptors. APV was used at $0.2 \mathrm{~mm}$, because it has been shown that this concentration is effective in blocking electrical activity in rat visual cortical slices evoked by application of NMDA (Currie et al., 1994). NBQX was used at twice the concentration of quisqualate to ensure the blockade of AMPA/kainate receptors, although equal-molarity NBQX is effective in blocking retinal electrical activity elicited by quisqualate (Cohen and Miller, 1994). When tested in our preliminary experiment with two cats, NBQX at $0.5 \mathrm{~mm}$ reduced the quisqualate-stimulated cAMP increase substantially, from $>500 \%$ to $\sim 250 \%$ in cat visual cortical slices. We used DHPG at $100 \mu \mathrm{M}$, because it was shown in our preliminary study that DHPG at this concentration was effective in increasing the cAMP level in cat visual cortical slices. In an attempt to activate only mGluR5, the mGluR antagonist MCPG (1 mM) was used in combination with 4C3HPG to block the activation of group II mGluRs by 4 C3HPG. To verify this, we compared the cAMP increase by this drug combination with $4 \mathrm{C} 3 \mathrm{HPG}$ alone. If the addition of MCPG suppresses the activation of group II mGluRs, the cAMP increase activated by 4C3HPG alone should be higher than by the drug combination. We found that this was the case (see Results for details).

The concentration of L-CCG-I was determined according to Nakanishi (1992), in which it was shown that L-CCG-I at $10 \mu \mathrm{M}$ was not very effective in activating a group I mGluR but was very effective in activating a group II mGluR. In our preliminary study, we tested L-CCG-I at $10 \mu \mathrm{M}$, and we also tested another agonist (DCG-IV) for group II mGluRs at 3 and 10 $\mu \mathrm{M}$ in combination with APV (0.2 mM). L-CCG-I and DCG-IV effectively reduced forskolin $(10 \mu \mathrm{M})$-stimulated cAMP increase; however, DCG-IV at $3 \mu \mathrm{M}$ was more effective than at $10 \mu \mathrm{M}$. Therefore, DCG-IV at $3 \mu \mathrm{M}$ in combination with $0.2 \mathrm{~mm}$ APV was used in the experiment. We also tested the group III-preferred agonist L-AP4 at $1 \mathrm{~mm}$ : forskolinstimulated cAMP was effectively suppressed by L-AP4 at this concentration.

During drug treatment, the incubation chambers were oxygenated and kept at $36^{\circ} \mathrm{C}$. The drug reaction was terminated by cooling the slice on an ice-cold aluminum plate. Slices without any drug treatment were processed alongside as a control. Because of the need for freshly prepared slices, experiments with different drug treatments on one animal were performed on the same day and data from different animals were collected on different days.

Incubation time for each mGluR agonist was $10 \mathrm{~min}$. When used, antagonists were applied for $10 \mathrm{~min}$ of pre-agonist incubation before co-incubation with the agonist (NBQX and APV before quisqualate and before the quisqualate, L-CCG-I and L-AP4 cocktail; APV before DCGIV; and MCPG before 4C3HPG). When tetrodotoxin (TTX; $1 \mu \mathrm{M}$ ) was used, it was also applied for pre- and co-incubation.

Six slices ( 3 slices per animal) were used to obtain results for each age group for each of ACPD, quisqualate, and no-drug treatments. Two slices ( 1 per animal) were used for each age group for each of the cocktails L-CCG-I, L-AP4, DHPG, the combination of 4C3HPG and MCPG, and the cocktail. One slice was used for each age group for DCG-IV and treatments with TTX.

The quantity of cAMP was measured by the RIA method (Harper and Brooker, 1975). Slices were homogenized in ice-cold $7 \%$ trichloroacetic acid (TCA) with a small amount of $\left[{ }^{3} \mathrm{H}\right] \mathrm{cAMP}$. After TCA was removed with ether extraction, the cAMP in the homogenate supernatant was assayed and corrected for $\left[{ }^{3} \mathrm{H}\right]$ cAMP recovery. cAMP was quantified using an acetylated procedure recommended by the vendor (Biomedical Technologies, Stoughton, MA). The pellet of each homogenate was assayed for the protein level (Lowry assay). The level of cAMP reported was expressed per unit of protein.

\section{RESULTS}

\section{Developmental change of ACPD-stimulated cAMP increase and basal cAMP level, and the effects of dark rearing}

The increase in cAMP by activation of mGluRs using ACPD (ACPD-stimulated cAMP minus basal cAMP) correlates closely with the critical period (Fig. 1) that has been established by examining the shift of ocular dominance after monocular deprivation (Olson and Freeman, 1980). The timing coincided with the critical period in that it peaked at 5 weeks of age, declined quickly within the next 10 weeks, then gradually tapered to a low level in the adult afterward. Furthermore, dark rearing had a similar effect on the ACPD-stimulated cAMP increase as on the critical period. The increase of cAMP level in dark-reared animals was lower than normal animals at 5 weeks and the same at 8.5 weeks, but it was higher at 15 weeks of age.

The effect of ACPD on the cAMP increase is probably not attributable to indirect receptor activation by action potentials generated by mGluR agonists, because TTX did not have a significant effect on ACPD-stimulated cAMP levels. We obtained the results of TTX-free and TTX-treated slices from the same animal (1 animal per age as plotted in Fig. 1) and then compared the overall effects across ages and rearing conditions (paired $t$ test, $t=-0.065$, df $=8, p=0.95)$. The average increase of cAMP by ACPD was $767.5 \pm 82.7 \mathrm{pmol} / \mathrm{mg}$ protein (mean \pm SEM) and by ACPD in the presence of TTX was 743.3 \pm 123.6.

The cAMP level increased by ACPD could be an amplification of the net basal cAMP formation and degradation, which is reflected by the basal cAMP level. If this is the case, one will find that the basal cAMP levels correlate with the ACPD-stimulated cAMP increase, but the percent increases in cAMP level by ACPD should be similar for all ages. We found that the basal cAMP level also correlated with the critical period around its peak. It peaked at 5 weeks of age (Fig. 2). The basal cAMP level of dark-reared animals was lower at 5 weeks and may have a 


\section{ACPD Elevated cAMP}

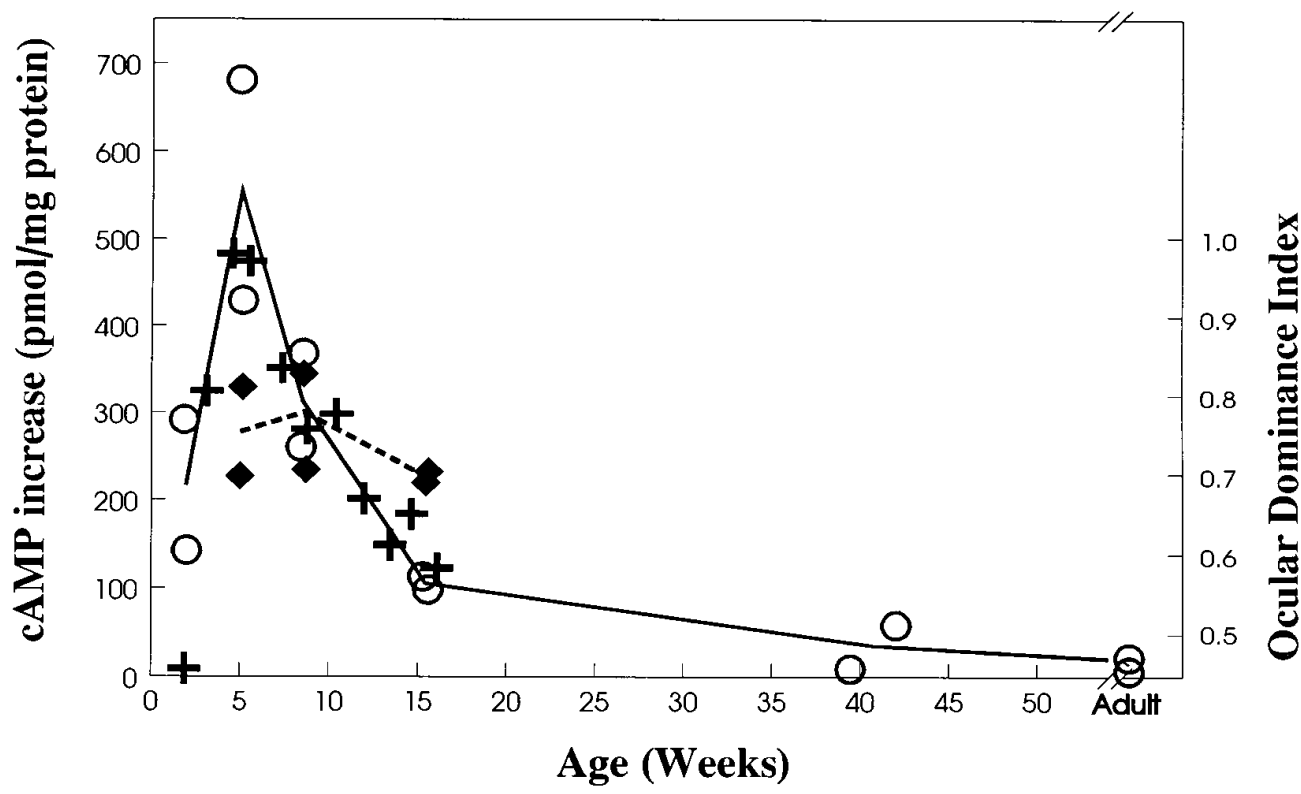

Figure 1. cAMP increases activated by ACPD correlate with the critical period for ocular dominance plasticity. cAMP increases were calculated as the elevated level of cAMP with the basal level subtracted. The cAMP increase produced by ACPD changes among normal animals of different ages. Dark rearing has similar effects on ACPD-elevated cAMP as on ocular dominance plasticity (Mower, 1991): the level is lower at 5 weeks but higher at 15 weeks of age in darkreared than normal animals. The solid line connects the means across ages of normal animals. The dashed line connects the means across ages of darkreared animals. + , Effects of monocular deprivation (Olson and Freeman, 1980) expressed as weighted ocular dominance, with 0.44 set at 0 , because this is the weighted ocular dominance found in normal animals (see Daw et al., 1992). Open symbols, Normal; filled symbols, dark-reared.

tendency to be higher at 15 weeks of age than normal animals. The basal cAMP level shows little decline after 9 weeks of age, whereas the ACPD-stimulated cAMP increase does show a substantial decline after 9 weeks of age. Calculation of the percent increases in cAMP level by ACPD in the normal animals gave $1169,1213,1043,444,140$, and $68 \%$ for 2-, 5-, 8.5-, 15-, and 41-week-old and adult cats, respectively. These values were close to each other at the youngest three ages (before 9 weeks of age) but show large reductions afterward. Thus, it seems that before 9 weeks of age, the basal cAMP production is the prime factor that contributes to the correlation between the cAMP increase by ACPD stimulation and changes in plasticity; however, after 9 weeks of age, other factors such as the quantities of mGluRs are the main contributors for the decline of ACPD-stimulated cAMP level and the decline of plasticity. These results are consistent with our previous findings that the quantities of mGluRs decline over development without peaking at 5 weeks of age (Reid et al., 1994, 1995b).

\section{Which mGluR group is responsible for enhancing basal cAMP activity?}

Activation of group I mGluRs is known to raise cAMP levels (Nakanishi, 1992; Joly et al., 1995), and quisqualate is the most potent agonist of group I mGluRs. Quisqualate also activates

\section{Basal cAMP Level}

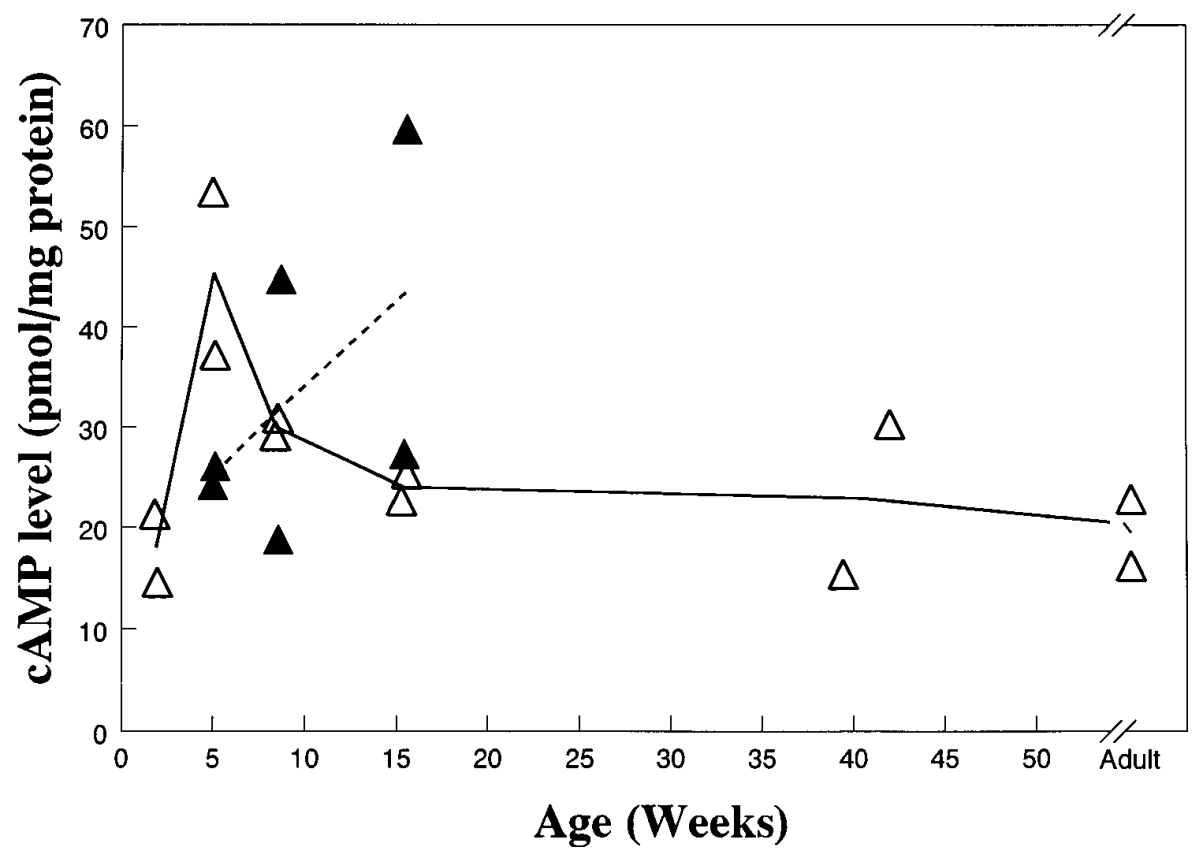

Figure 2. Basal levels of cAMP are highest at the peak of the critical period for ocular dominance plasticity. The basal cAMP levels changes with age in normal animals. Dark rearing has similar effects on the basal cAMP level as on ocular dominance plasticity: the level is lower at 5 weeks but may have a tendency to be higher at 15 weeks of age in dark-reared than normal animals. The solid line connects the means across ages of normal animals. The dashed line connects the means across ages of dark-reared animals. Open symbols, Normal; filled symbols, dark-reared. 


\section{Quisqualate + NBQX + APV}

Figure 3. Levels of cAMP increased by activating group I mGluR by quisqualate vary with age but do not correlate with the critical period as well as those activated by ACPD. Dark rearing had little effect on the quisqualate-induced cAMP increase. The solid line connects the means across ages of normal animals. The dashed line connects the means across ages of dark-reared animals. Open symbols, Normal; filled symbols, dark-reared.

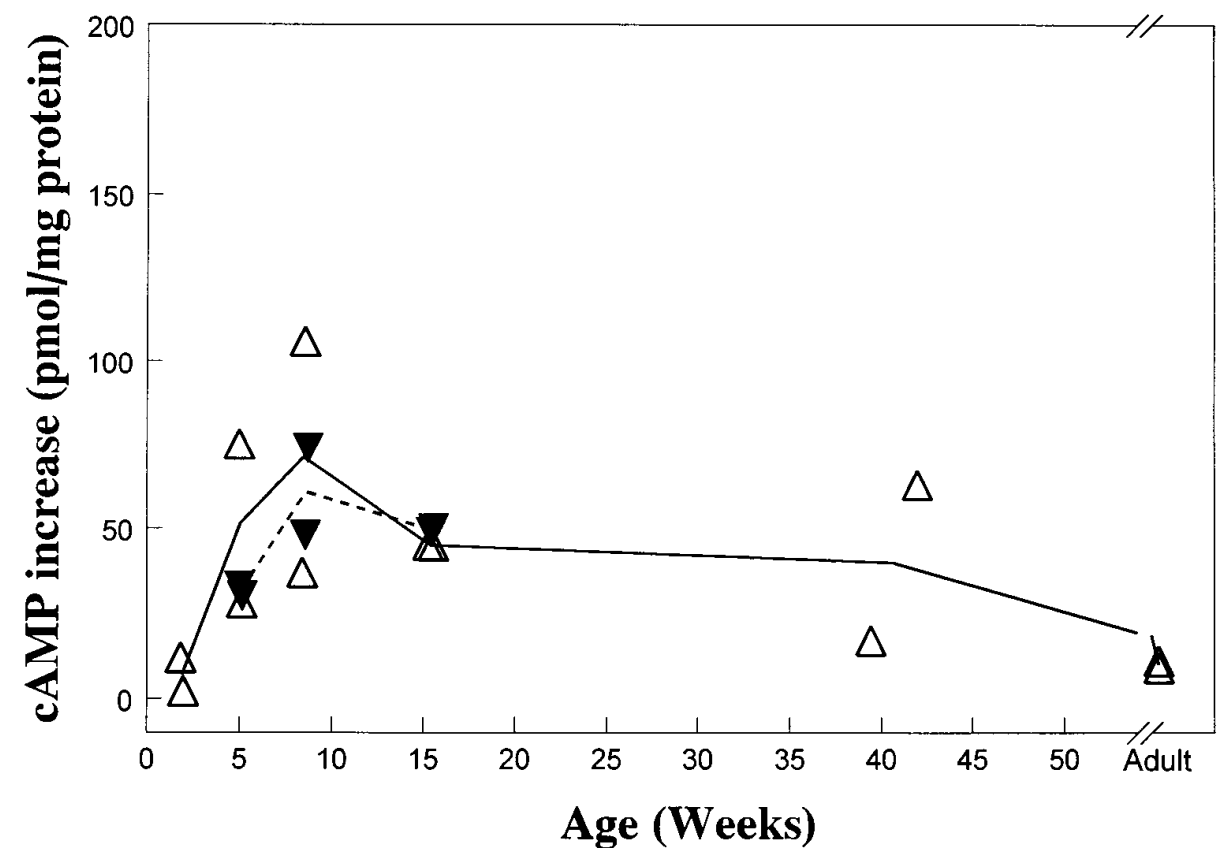

cAMP increase by this drug combination with 4C3HPG alone. The addition of MCPG significantly reduced cAMP increase by 4C3HPG from $64.27 \pm 26.48$ to $20.46 \pm 21.35 \%$ (paired $t$ test, $t=$ -2.462 , df $=10, p<0.05)$.

The above results show that application of agonists that activate mainly group I mGluRs did not emulate the effect of ACPD. ACPD can activate all three mGluR groups in a high concentration such as was used in our study (Schoepp and Conn, 1993). When we used a cocktail composed of quisqualate to activate group I receptors, L-CCG-I to activate group II receptors and L-AP4 to activate group III receptors, the cocktail mixture was more effective in elevating the cAMP level than any of its individual components used alone (Fig. 4). The cocktail had a superadditive effect in that it raised the cAMP level higher than the sum of the individual components in all tested ages (paired $t$ test, $t=$ $5.684, \mathrm{df}=17, p<0.001)$. Neither the group II mGluR-preferring agonist L-CCG-I (Hayashi et al., 1992; Winder and Conn, 1995) nor the group III-preferring agonist L-AP4 (Nakajima et al., 1993; Tanabe et al., 1993) provided a pattern of agonist-induced cAMP increase correlated with the critical period (Fig. 4). On the other hand, the developmental pattern and effects of dark rearing on cAMP level were similar for both the cocktail and ACPD.

It is known that activation of either group II or group III mGluRs suppresses the forskolin-elevated cAMP level (Tanabe et al., 1992, 1993; Nakajima et al., 1993; Okamoto et al., 1994). DCG-IV is specific to group II mGluRs when it is used in combination with APV to suppress its effect on NMDA receptors (Hayashi et al., 1993; Gereau and Conn, 1995). When the group II agonists L-CCG-I and DCG-IV were tested without forskolin, they elevated the cAMP level significantly above the basal level (paired $t$ test, $t=2.176$, df $=17, p<0.05$ for L-CCG-I; $t=2.431$, $\mathrm{df}=8, p<0.05$ for DCG-IV; Fig. 5). Both agonists raised the cAMP level by $\sim 50 \%$. On the other hand, L-CCG-I had little effect on the forskolin-elevated cAMP level (paired $t$ test, $t=$ -0.479 , df $=8, p=0.645$; Fig. 5). DCG-IV, when it was combined

with APV, depressed the forskolin effect (paired $t$ test, $t=3.244$, cal period (data not shown). To verify that MCPG was pressing the activation of group II mGluRs, we compared the 


\section{Super-additive effects of mGluR agonists}

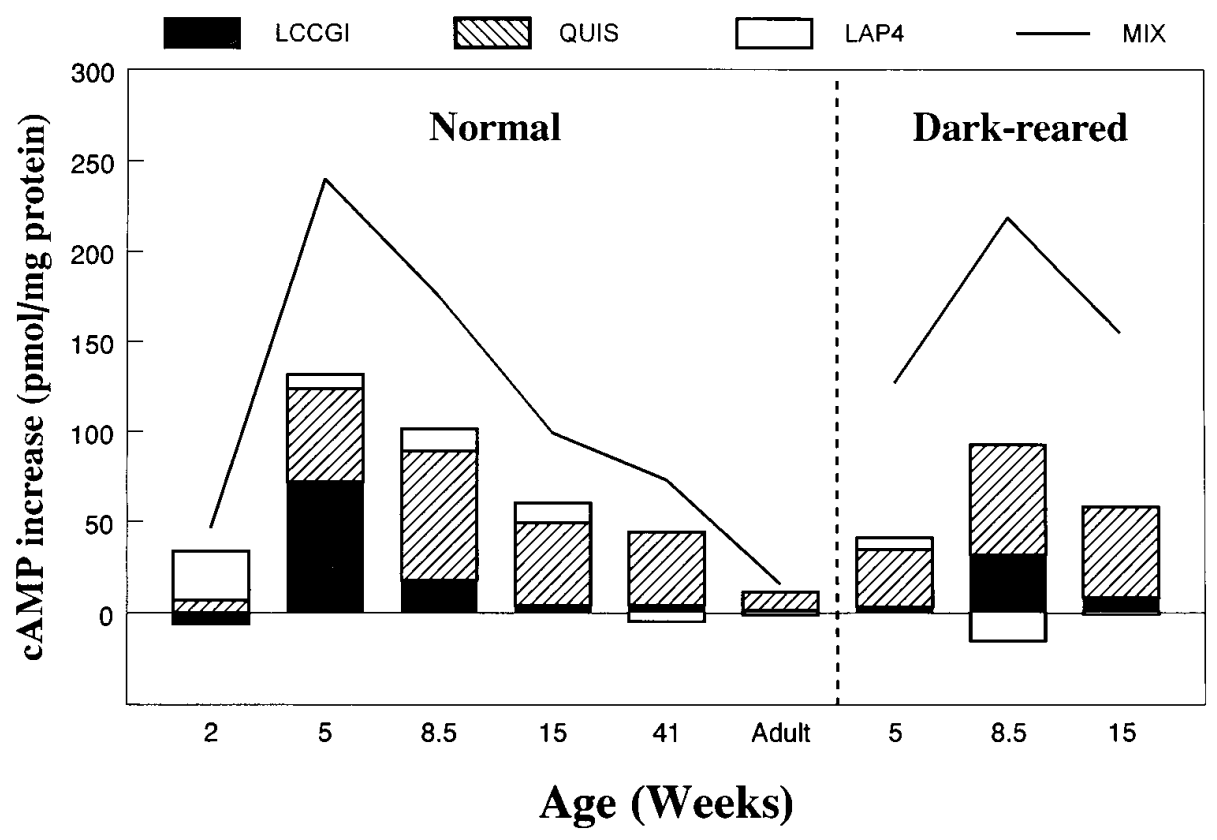

Figure 4. Super-additive effects of mGluR agonists on cAMP levels. Regardless of ages and rearing conditions, when three mGluR agonists were mixed together in the same concentration as used separately, the mixture (MIX, line graph) was more effective in increasing the cAMP level than adding together the results of individual agonists (bar graph; paired $t$ test, $t=5.684, \mathrm{df}=$ $17, p<0.001)$. cAMP increases produced by the mixture correlate with the critical period for ocular dominance plasticity in normal and darkreared animals, but cAMP increases produced by individual components do not. QUIS, Quisqualate + NBQX + APV; LCCGI, L-CCG-I; LAP4, L-AP4. $\mathrm{df}=8, p<0.05$; Fig. 5). This depression on forskolin-stimulated cAMP increase was also found with L-AP4 (paired $t$ test, $t=$ -5.921 , df $=8, p<0.001$; Fig. 5). The effect of these drugs was small: 27 and $30 \%$ depression, respectively.

\section{DISCUSSION}

In this study, we found that the developmental time course of the cAMP increase generated by ACPD stimulation fits very well with the critical period for monocular deprivation (Olson and Freeman, 1980). Furthermore, our results on the effects of dark rearing on this cAMP increase also fit the prediction by Mower's study that dark rearing should have an age-dependent effect on a factor involved in ocular dominance plasticity (Mower, 1991). In addition to some results on ibotenate-stimulated PI turnover (Dudek and Bear, 1989) and the immediate-early gene EGR-1 (Kaplan et al., 1995), we have applied the results of Mower (1991) successfully to demonstrate a factor that correlates with the critical period in both light- and dark-reared animals over a range of ages including those at which dark-reared animals are less plastic than normal, as well as ages at which they are more plastic than normal. The effects of ACPD are not likely to be attributable to indirect receptor activation by action potentials, because incubation with TTX did not suppress the effect of ACPD on cAMP increase. However, we do not exclude the possibility that action potentials may make a small contribution at some of the ages. Although it is beyond the scope of the current paper, it would also be interesting to examine in the future the developmental changes in cAMP increase with the endogenous mGluR agonist glutamate. Nevertheless, the close correlation found in our study does suggest that mGluRs may participate in ocular dominance plasticity by modulating the level of the messenger, cAMP.

Our results show that activation of group II mGluRs produces an increase in cAMP. There is also a decrease in forskolinstimulated levels of cAMP, but the increase above basal levels is larger than the decrease in forskolin-stimulated levels. Moreover, regulation of basal cAMP levels is the predominant effect of
mGluR activation in young animals in rat hippocampus and rat visual cortex (Casabona et al., 1992; Schoepp and Johnson, 1993; Flavin et al., 1996). The increase above basal levels from activation of group II mGluRs has been seen in other preparations (Winder and Conn, 1995; Schoepp et al., 1996; Flavin et al., 1996) and is probably attributable to an interaction between G-protein subunits controlled by group II mGluRs and G-protein subunits controlled by other neurotransmitters such as adenosine (Schoepp and Johnson, 1993; Winder and Conn, 1993; Schoepp et al., 1996). The increase above basal levels is not seen in transfected cells (Nakanishi, 1992), because they do not contain these other components of the intact system.

Activation of either group I or group II mGluRs can increase cAMP. Both group I agonists and group II agonists tested in this study raised cAMP levels. Moreover, when all three mGluR groups were activated together by an agonist cocktail, the increase in cAMP was larger than the sum of the individual components, suggesting a synergistic effect. A similar result has been found in the hippocampus (Schoepp et al., 1996). This super-additive effect, like the increase of cAMP generated by group II mGluR activation, indicates an interaction between pathways. Besides $\mathrm{G}_{\alpha}$-protein subunits, the activity of adenylyl cyclase could also be influenced by protein kinase $\mathrm{C}, \mathrm{Ca}^{2+}$, and $\beta \gamma$ subunits of G-proteins. The increase of cAMP in the hippocampus by activation of mGluRs is likely caused by a stimulatory effect of $\beta \gamma$ subunits of G-proteins (Winder and Conn, 1993) rather than an indirect effect of $\mathrm{Ca}^{2+}$ on $\mathrm{Ca}^{2+} /$ calmodulin-dependent adenylyl cyclase (Winder and Conn, 1995). On the other hand, it has been demonstrated in Aplysia that an increase of intracellular $\mathrm{Ca}^{2+}$ can elevate cAMP level by activation of $\mathrm{Ca}^{2+} /$ calmodulin-dependent adenylyl cyclase (Abrams et al., 1991). Both $\mathrm{Ca}^{2+}$-sensitive type I adenylyl cyclase and $\beta \gamma$ subunit-sensitive type II adenylyl cyclase (which is also stimulated by protein kinase C) are present in the cortex (Mons et al., 1993). The presence of these adenylyl cyclases allows an indirect pathway to elevate cAMP level through PI 

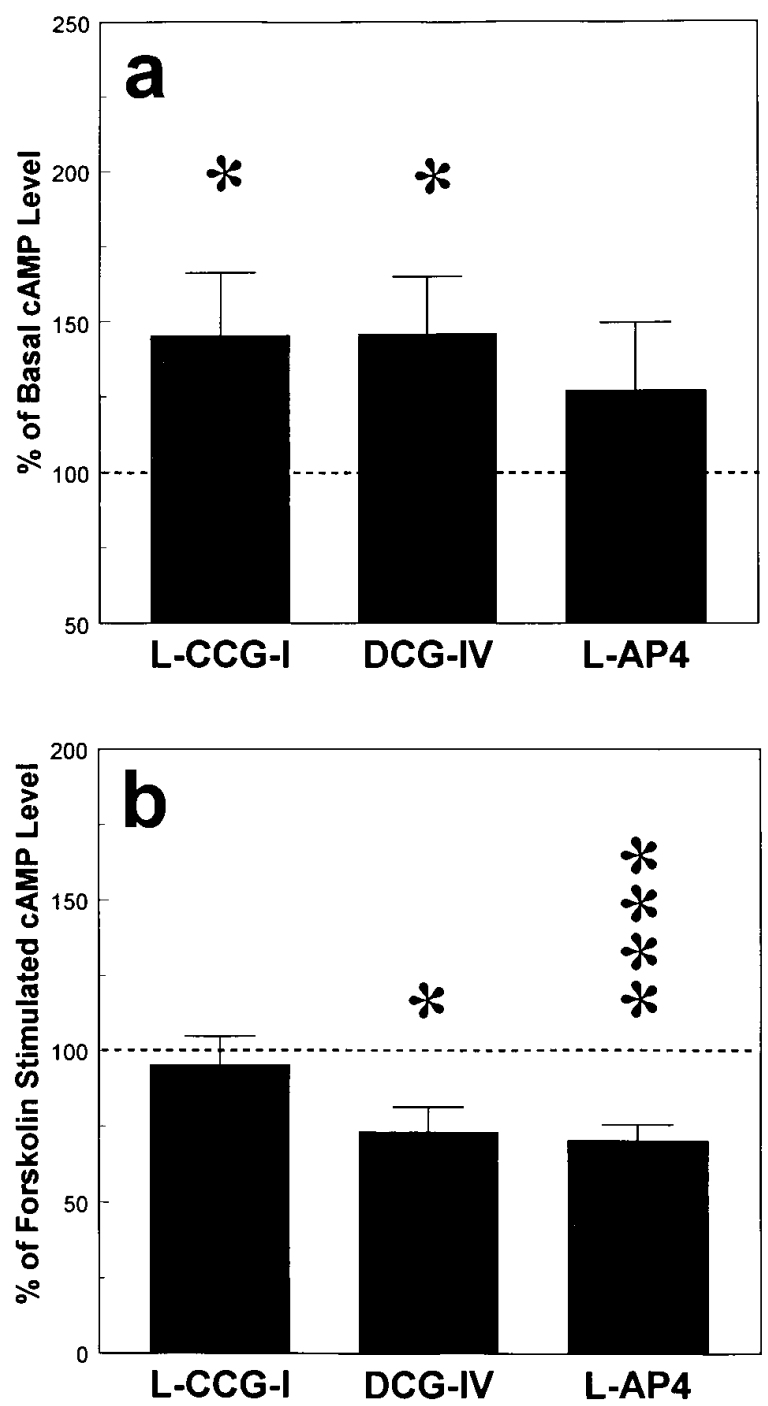

Figure 5. Effects of group II (L-CCG-I and DCG-IV) and group III (L-AP4) mGluR agonists on cAMP levels. $a$, Both L-CCG-I and DCG-IV elevated cAMP levels by $46 \%$ without the presence of forskolin. L-AP4 had little effect on elevating cAMP level. $b$, L-CCG-I had little effect on the forskolin-elevated cAMP level. Both DCG-IV and L-AP4 suppressed the forskolin-elevated cAMP levels by 27 and $30 \%$, respectively. ${ }^{*} p<0.05$; $* * * * p<0.001$.

hydrolysis and also provides potential sites for interaction when different receptors are activated.

The best correlation between cAMP increases and critical period was not found with activation of group I mGluRs alone. When primarily group I mGluRs were activated by quisqualate, cAMP increases peaked after the peak of the critical period. The combination of $4 \mathrm{C} 3 \mathrm{HPG}$ and MCPG had very little effect on cAMP level. Because activation of group I mGluRs are known to increase intracellular $\mathrm{Ca}^{2+}$, these results also indicate that the correlation of cAMP increase with the critical period cannot be accounted for solely by activation of adenylyl cyclase through the mGluR-linked $\mathrm{Ca}^{2+}$ signal transduction pathway. Activation of primarily group II mGluRs by L-CCG-I or primarily group III mGluRs by L-AP4 also did not lead to a cAMP increase correlated with the critical period. A better correlation was found when all groups of mGluRs were activated. This result suggests that the super-additive interaction between the various types of mGluR is important for the overall function of the system.

The increase in cAMP generated by mGluR activation is determined partly by the number of mGluR receptors and partly by the basal activity of cAMP production controlled by synthesis and degradation. In our previous work, we found that the quantities of mGluR1, mGluR2/3, and mGluR5, measured on Western blots with specific antibodies, declined steadily from birth (Reid et al., 1994, 1995b). There was a decrease rather than an increase between birth and 4 weeks of age, during the period when the cortex is becoming more plastic. In the current work, we found that the basal cAMP level increases over this period and thus correlates with the early part of the critical period better than the number of mGluR receptors. The difference in time course between the cAMP increase generated by mGluR activation and the basal cAMP level is that the former drops to very low levels in the adult, as compared to the level at the peak of the critical period, whereas the latter does not. Therefore, the decline of the mGluRstimulated cAMP level in the older animals ( $>8.5$ weeks of age) is likely to be attributable mainly to the reduced mGluR quantity. Thus, the correlation between ACPD-stimulated increases in cAMP and the critical period for plasticity in both light- and dark-reared animals depends primarily on variations in the basal activity of cAMP production between birth and 9 weeks of age, and variations in the number of receptors becomes important after that. The combination of these two factors leads to the closest correlation.

Several years ago, Dudek and Bear (1989) showed that increases in phosphoinositides produced by ibotenate correlate with the critical period for plasticity in normal animals. Furthermore, this PI turnover in dark-reared kittens is lower than normal kittens at 5 weeks of age but equal to normal kittens at 8 and 15 weeks of age. Their data fit the prediction by Mower's study at 5 and 8 weeks of age. This was interpreted as an effect of the metabotropic glutamate receptors (mGluR1 and mGluR5) that affect PI, because increases in PI produced by carbachol did not show the same effects. When the quantities of mGluR1 and mGluR5 were measured, the quantities did not correlate with the critical period (Reid et al., 1994, 1995b); however, the mGluRactivated PI turnover correlates with the critical period (Dudek and Bear, 1989). Here also it is the amount of second-messenger generated by activation of receptors that is important, and/or the coupling between receptor and second messenger, rather than the amount of receptor.

Ocular dominance plasticity is governed by visual activity coming from the retina (Stryker and Harris, 1986), carried by the transmitter glutamate, and modulated by activity from other sources, carried by the transmitters acetylcholine and noradrenaline (Bear and Singer, 1986; Imamura and Kasamatsu, 1989; Brocher et al., 1992; Gu and Singer, 1993). All of these transmitters affect cAMP (Bourne and Nicoll, 1993). Our results that the basal cAMP level and levels of cAMP raised by metabotropic glutamate receptors are closely related to ocular dominance plasticity in both light- and dark-reared animals suggest that modulation of cAMP level could be critical in plasticity. The correlation of basal cAMP level also suggests that cAMP could be where various factors can converge on and exert their influence on plasticity, as also suggested by Kandel's group for the hippocampus (Abrams et al., 1991).

A recent paper by Hensch and Stryker (1996) shows that infusion of the metabotropic antagonist MCPG into the visual cortex does not affect ocular dominance plasticity. However, it 
does affect long-term depression, as shown previously (Kato, 1993; Haruta et al., 1994). Hensch and Stryker (1996) showed that MCPG acted as an antagonist for some mGluR effects in their system, but they did not test all mGluR effects. Their result would also have occurred if factors other than mGluRs affect cAMP to influence ocular dominance plasticity.

In summary, we have shown that levels of both mGluR-elevated and basal cAMP levels in the cat visual cortex fit the time course of plasticity well in both light- and dark-reared animals, the basal levels of cAMP being the prime determinant of the peak of the critical period. cAMP is likely to be a messenger of mGluRs for ocular dominance plasticity. Activation of multiple mGluR groups together can enhance basal cAMP activity and leads to a correlation with the critical period. Therefore, both basal cAMP production and activation of mGluRs are important factors in visual cortical plasticity. Similarly, it is likely that other factors may also converge to modulate cAMP level; therefore, cAMP could well be the common path through which various factors affect plasticity.

\section{REFERENCES}

Abrams TW, Karl KA, Kandel ER (1991) Biochemical studies of stimulus convergence during classical conditioning in Aplysia: dual regulation of adenylate cyclase by $\mathrm{Ca}^{2+} /$ calmodulin and transmitter. J Neurosci 11:2655-2665.

Antonini A, Stryker MP (1993) Rapid remodelling of axonal arbors in the visual cortex. Science 260:1819-1821.

Bashir ZI, Bortolotto ZA, Davies CH, Berretta N, Irving AJ, Seal AJ, Henley JM, Jane DE, Watkins JC, Collingridge GL (1993) Induction of LTP in the hippocampus needs synaptic activation of glutamate metabotropic receptors. Nature 363:347-350.

Bear MF, Singer W (1986) Modulation of visual cortical plasticity by acetylcholine and noradrenaline. Nature 320:172-176.

Behnisch T, Reymann KG (1993) Co-activation of metabotropic glutamate and $\mathrm{N}$-methyl-D-aspartate receptors is involved in mechanisms of long-term potentiation maintenance in rat hippocampal CA1 neurons. Neuroscience 54:37-47.

Bourne HR, Nicoll R (1993) Molecular machines integrate coincident synaptic signals. Cell 72:65-75.

Brocher S, Artola A, Singer W (1992) Agonists of cholinergic and noradrenergic receptors facilitate synergistically the induction of long-term potentiation in slices of rat visual cortex. Brain Res 573:27-36.

Casabona G, Genazzani AA, Di Stefano M, Sortino MA, Nicoletti F (1992) Developmental changes in the modulation of cyclic AMP formation by the metabotropic glutamate receptor agonist $1 \mathrm{~S}, 3 \mathrm{R}$ aminocyclopentane-1,3-dicarboxylic acid in brain slices. J Neurochem 59:1161-1163.

Cohen ED, Miller RF (1994) The role of NMDA and non-NMDA excitatory amino acid receptors in the functional organization of primate retinal ganglion cells. Vis Neurosci 11:317-332.

Currie SN, Wang XF, Daw NW (1994) NMDA receptors in layers II and III of rat cerebral cortex. Brain Res 662:103-108.

Cynader M, Mitchell DE (1980) Prolonged sensitivity to monocular deprivation in dark-reared cats. J Neurophysiol 43:1026-1040.

Daw NW, Fox K, Sato H, Czepita D (1992) Critical period for monocular deprivation in the cat visual cortex. J Neurophysiol 67:197-202.

Dudek SM, Bear MF (1989) A biochemical correlate of the critical period for synaptic modification in the visual cortex. Science 246:673-675.

Flavin HJ, Daw NW, Gregory DS, Reid SNM (1996) Glutamate receptors and development of the visual cortex: effect of metabotropic agonists on cAMP. Prog Brain Res 108:263-272.

Frank DA, Greenberg ME (1994) CREB: a mediator of long-term memory from mollusks to mammals. Cell 79:5-8.

Frey U, Huang YY, Kandel ER (1993) Effects of cAMP simulate a late stage of LTP in hippocampal CA1 neurons. Science 260:1661-1664.

Gereau RW, Conn PJ (1995) Roles of specific metabotropic glutamate receptor subtypes in regulation of hippocampal CA1 pyramidal cell excitability. J Neurophysiol 74:122-129.

Gu Q, Singer W (1993) Effects of intracortical infusion of anticholinergic drugs on neuronal plasticity in kitten striate cortex. Eur J Neurosci $5: 475-485$.
Harper JF, Brooker G (1975) Femtomole sensitive radioimmunoassay for cyclic AMP and cyclic GMP after $2^{\prime} 0$ acetylation by acetic anhydride in aqueous solution. J Cyclic Nucleotide Res 1:207-218.

Hartell NA (1994) Induction of cerebellar long-term depression requires activation of glutamate metabotropic receptors. NeuroReport 5:913-916.

Haruta H, Kamishita T, Hicks TP, Takahashi MP, Tsumoto T (1994) Induction of LTD but not LTP through metabotropic glutamate receptors in visual cortex. NeuroReport 5:1829-1832.

Hayashi Y, Momiyama A, Takahashi T, Ohishi H, Ogawa-Meguro R, Shigemoto R, Mizuno N, Nakanishi S (1993) Role of a metabotropic glutamate receptor in synaptic modulation in the accessory olfactory bulb. Nature 366:687-690.

Hensch TK, Stryker MP (1996) Ocular dominance plasticity under metabotropic glutamate receptor blockade. Science 272:554-557.

Hubel DH, Wiesel TN, LeVay S (1977) Plasticity of ocular dominance columns in monkey striate cortex. Philos Trans R Soc Lond [Biol] 278:377-409.

Imamura K, Kasamatsu T (1989) Interaction of noradrenergic and cholinergic systems in regulation of ocular dominance plasticity. Neurosci Res 6:519-536.

Joly C, Gomeza J, Brabet I, Curry K, Bockaert J, Pin JP (1995) Molecular, functional, and pharmacological characterization of the metabotropic glutamate receptor type 5 splice variants: comparison with mGluR1. J Neurosci 15:3970-3981.

Kaplan IV, Guo Y, Klueber K, Mower GD (1995) Developmental expression of the immediate early gene EGR-1 mirrors the critical period in cat visual cortex. Soc Neurosci Abstr 21:1793.

Kato N (1993) Dependence of long-term depression on postsynaptic metabotropic glutamate receptors in visual cortex. Proc Natl Acad Sci USA 90:3650-3654.

Matthies H, Reymann KG (1993) Protein kinase A inhibitors prevent the maintenance of hippocampal long-term potentiation. NeuroReport 4:712-714.

McGuinness N, Anwyl R, Rowan M (1991) Trans-ACPD enhances longterm potentiation in the hippocampus. Eur J Pharmacol 197:231-232.

Mons N, Yoshimura M, Cooper DMF (1993) Discrete expression of $\mathrm{Ca}^{2+} /$ calmodulin-sensitive and $\mathrm{Ca}^{2+}$-insensitive adenylyl cyclases in the rat brain. Synapse 14:51-59.

Mower GD (1991) The effect of dark rearing on the time course of the critical period in cat visual cortex. Dev Brain Res 58:151-158.

Musgrave MA, Ballyk BA, Goh JW (1993) Coactivation of metabotropic and NMDA receptors is required for LTP induction. NeuroReport 4:171-174.

Nakajima Y, Iwakabe H, Akazawa C, Nawa H, Shigemoto R, Mizuno N, Nakanishi S (1993) Molecular characterization of a novel retinal metabotropic glutamate receptor mGluR6 with a high agonist selectivity for L-2-amino-4-phosphonobutyrate. J Biol Chem 268:11868-11873.

Nakanishi S (1992) Molecular diversity of glutamate receptors and implications for brain function. Science 258:597-603.

Okamoto N, Hori S, Akazawa C, Hayashi Y, Shigemoto R, Mizuno N, Nakanishi S (1994) Molecular characterization of a new metabotropic glutamate receptor mGluR7 coupled to inhibitory cyclic AMP signal transduction. J Biol Chem 269:1231-1236.

Olson CR, Freeman RD (1980) Profile of the sensitive period for monocular deprivation in kittens. Exp Brain Res 39:17-21.

Otani S, Ben-Ari Y (1991) Metabotropic receptor-mediated long-term potentiation in rat hippocampal slices. Eur J Pharmacol 205:325-326.

Reid SNM, Romano C, Hughes T, Daw NW (1994) Distribution of phosphoinositide (PI)-linked metabotropic glutamate receptors (mGluR1 $\alpha$ and mGluR5) in the cat visual cortex and their involvement in the critical period for eye specific connections. Soc Neurosci Abstr 20:276.

Reid SNM, Romano C, Hughes T, Daw NW (1995a) Immunohistochemical study of two phosphoinositide-linked metabotropic glutamate receptors (mGluR1 $\alpha$ and mGluR5) in the cat visual cortex before, during and after the peak of the critical period for eye-specific connections. J Comp Neurol 355:470-478.

Reid SNM, Romano C, Hughes T, Devlin D, Daw NW (1995b) Development of cAMP-linked metabotropic glutamate receptor (mGluR2/3) and dark-rearing influence on mGluRs $(1,2 / 3$ and 5) in the cat visual cortex. Soc Neurosci Abstr 21:2024.

Schacher S, Castellucci VF, Kandel ER (1988) cAMP evokes long-term facilitation in Aplysia sensory neurons that requires new protein synthesis. Science 240:1667-1669. 
Schoepp DD, Conn PJ (1993) Metabotropic glutamate receptors in brain function and pathology. Trends Pharmacol Sci 14:13-20.

Schoepp DD, Johnson BG (1993) Metabotropic glutamate receptor modulation of cAMP accumulation in the neonatal rat hippocampus. Neuropharmacology 32:1359-1365.

Schoepp DD, Johnson BG, Monn JA (1996) (1S,3R)-1- Aminocyclopentane-1,3-dicarboxylic acid-induced increases in cyclic AMP formation in the neonatal rat hippocampus are mediated by a synergistic interaction between phosphoinositide- and inhibitory cyclic AMP-coupled mGluRs. J Neurochem 66:1981-1985.

Shatz CJ, Stryker MP (1978) Ocular dominance in layer IV of the cat's visual cortex and the effects of monocular deprivation. J Physiol (Lond) 281:267-283.

Stevens CF (1994) CREB and memory consolidation. Neuron 13:769-770.

Stryker MP, Harris WA (1986) Binocular impulse blockade prevents the formation of ocular dominance columns in cat visual cortex. $\mathrm{J}$ Neurosci $6: 2117-2133$.
Tanabe Y, Masu M, Ishii T, Shigemoto R, Nakanishi S (1992) A family of metabotropic glutamate receptors. Neuron 8:169-179.

Tanabe Y, Nomura A, Masu M, Shigemoto R, Mizuno N, Nakanishi S (1993) Signal transduction, pharmacological properties, and expression patterns of two rat metabotropic glutamate receptors, mGluR3 and mGluR4. J Neurosci 13:1372-1378.

Valverde F (1968) Structural changes in the area striata of the mouse after enucleation. Exp Brain Res 5:274-292.

Wiesel TN, Hubel DH (1963) Single-cell responses in striate cortex of kittens deprived of vision in one eye. J Neurophysiol 26:1003-1017.

Winder DG, Conn PJ (1993) Activation of metabotropic glutamate receptors increases cAMP accumulation in hippocampus by potentiating responses to endogenous adenosine. J Neurosci 13:38-44.

Winder DG, Conn PJ (1995) Metabotropic glutamate receptor (mGluR)-mediated potentiation of cyclic AMP responses does not require phosphoinositide hydrolysis: mediation by a Group II-like mGluR. J Neurochem 64:592-599. 